\title{
Evaluation of Efficacy and Safety After Replacement of Methyl Hydrogen With Deuterium at 7-position Methyl Formate of Clopidogrel
}

\section{Zhiping Xu}

Jilin University

Yujia Miao

Jilin University

Tianlong Wu

Jilin University

Liang Chen

Jilin University

Mingyue Gao

Jilin University

\section{Yantong Sun}

Jilin University

Yingze Liu

Jilin University

Jinjin Niu

Jilin University

Deqi Cai

Jilin University

Xiaohua Li

Jilin University

Chen Chen

Jilin University

\section{Shengyang Liu}

Yantai University

Jingkai Gu

Jilin University

Xia Cao ( $\nabla$ caoxia@jlu.edu.cn )

Department of Pharmacology, School of Pharmacy, Jilin University https://orcid.org/0000-0002-26689374 
Keywords: Deuterium clopidogrel, Platelet aggregation, Active metabolite, Cytochrome P450 enzymes, Hepatocyte apoptosis

Posted Date: April 8th, 2021

DOI: https://doi.org/10.21203/rs.3.rs-383891/v1

License: (c) (1) This work is licensed under a Creative Commons Attribution 4.0 International License. Read Full License 


\section{Abstract}

\section{Background and Purpose}

As a first-line clinical drug, thienopyridines still have many unsatisfactory aspects, such as the low bioavailability of clopidogrel and the high bleeding risk of prasugrel. Our team synthesized deuterium clopidogrel(the patent has been obtained in China) to alleviate the deficiency of CLP in clinical application, such as a slow onset, greater influence of gene polymorphism and drug-drug interaction.

\section{Experimental Approach}

Molecular docking technology was used to analyze the affinity between deuterium clopidogrel and $\mathrm{P} 2 \mathrm{Y}_{12}$ receptor; The levels of active metabolites of deuterium clopidogrel in vivo were detected by HPLC/MS-MS and the activities of main metabolic enzymes was analyzed; Subsequently, platelet aggregation function, thrombus model were used to evaluate the pharmacodynamics of deuterium clopidogrel; Finally, the safety of deuterium clopidogrel were evaluated by blood routine, PT, APTT, bleeding time, serological tests, liver pathological biopsy, liver cell apoptosis and apoptosis-related protein detection.

Key Results

The introduction of deuterium makes the binding of clopidogrel to $\mathrm{P} 2 \mathrm{Y}_{12}$ receptor more stable, improves the concentration of active metabolites, reduces the inhibition of major metabolic enzymes including CYP2B6, CYP2C9 and CYP2C19, leading to the better anti-platelet effect without increasing the risk of bleeding, and leads to the decrease in the degree of hepatocyte apoptosis.

\section{Introduction}

Thrombosis can lead to heart, brain and pulmonary circulation diseases such as acute myocardial infarction, stroke and pulmonary embolism, seriously threatening human health and life ${ }^{[1]}$. It is likewise a common complication in surgical operations and the cause of re-occlusion after interventional angioplasty $[2,3]$. Thrombosis is the key factor leading to this kind of disease, so the development of drugs to prevent and treat thromboembolic diseases has become the focus of attention and research in the field of medicine.

Platelets play a major role in the process of thrombus formation ${ }^{[4]}$. Adenosine diphosphate(ADP) receptors on platelets can augment or amplify other platelet agonists, and ADP receptor antagonists have been a hot spot of research and development. ADP receptors mainly include $P 2 Y_{1}, P 2 Y_{12}$ and $P 2 X_{1}{ }_{1}^{[5-6]}$, among which, $\mathrm{P} 2 \mathrm{Y}_{12}$ receptor is the main target of $\mathrm{ADP}$ receptor antagonists, and $\mathrm{P} 2 \mathrm{Y}_{12}$ receptor antagonists are a class of drugs that act on platelet $P 2 Y_{12}$ receptor and inhibit platelet aggregation caused by $A D P{ }^{[7]}$. As a $P 2 Y_{12}$ receptor antagonist, clopidogrel(CLP) is the most commonly used antiplatelet aggregation drug in clinical practice. However, it has a few defects, such as low bioavailability 
and susceptibility to gene polymorphism ${ }^{[8-10]}$. Therefore, it is of great significance to find more safe, effective and bioavailable antithrombotic drugs.

Isotopes are atoms of the same chemical element with different masses due to the number of neutrons in the nucleus, resulting in isotopes of different atomic weight ${ }^{[11]}$. According to physical characteristics, isotopes can be subdivided into stable and radioactive forms. Radioactive isotopes decay over time and give off radiant energy, so they are unstable and their application scope is formally limited ${ }^{[12]}$. However, stable isotopes in nature are not radioactive and have durable physical properties, so they are harmless to the human body ${ }^{[13-14]}$.

Deuterium, a stable isotope with stable physical properties, has no bearing on the body at blood concentrations of 15 to 20 percent. Introducing deuterium into a drug molecule, which has the same shape and volume as hydrogen, generally does not change the drug's properties, therefore, deuteration is widely used in the drug development process, which can optimize some drugs with unsatisfactory effect $^{[15-17]}$. Deuterium debenazine (Teva) is a deuterium (-OCD3) substitute in which the hydrogen $(H)$ atoms of two methyl groups (-OCH3) are replaced by its isotope deuterium (D). Deuterium debenazine approved by the US FDA for the treatment of Huntington's Disease on April 3, 2017, and was the first deuterium substitute approved by the FDA ${ }^{[18-20]}$.

Given the disadvantages of CLP in clinical application and the advantages of deuterium in drug research, our team synthesized deuterium clopidogrel(D-CL) by structural modification of the clinical P2 $\mathrm{Y}_{12}$ receptor antagonist clopidogrel using deuterium generation technology (Fig.1A). The purpose of this study is to further study the influence of deuterium introduction on CLP and to provide research ideas and the basis for future research and development of new antithrombotic drugs.

\section{Methods}

\subsection{Chemicals}

Clopidogrel(CLP) were purchased from Sanofi (Hangzhou) Pharmaceutical Co., Ltd.; Deuterium clopidogrel(D-CL) were synthesized by Drug Metabolism Research Institute Beijing, after HPLC analysis and MS identification, the purity of deuterium clopidogrel reached $99.5 \%$; Sodium carboxymethyl cellulose(CMC), formalin, Sucrose, phenylmethanesulfonyl fluoride(PMSF), potassium pyrophosphate, Tris, dithiothreitol(DTT), triphosphopyridine nucleotide(NADPH), ethylenediamine tetraacetic acid(EDTA), and glycerol were obtained from Sinopharm Chemical Reagent Co., Ltd.; The drugs used in the experiment were all dissolved with $0.5 \% \mathrm{CMC}$-Na; 3'-methoxyphenacyl bromide(MPB)(TCl, Japan); Clopidogrel active metabolite methoxyacetophenone derivative(MP-AM)(TRC Canada); phenacetin, acetaminophen, bupropion, hydroxybupropione, paclitaxel, 6-Hydroxytaxol, tolbutamide, 4Hydroxytolbutamide, S-mephenytoin, 4-Hydroxymephenytoin, dextromethorphan, dextrorphan D-tartrate, testosterone and 6- $\beta$-hydroxytestosterone were purchased from Shanghai Canspec Scientific \& Technology Co., Ltd.; BCA Protein Assay Kit were purchased from Beyotime Biotechnology Co., Ltd.; 
Platelet aggregation function test kit (ADP-activated light transmission platelet aggregometry) were obtained from Techlink Biomedical Technology Co., Ltd.; Hematoxylin and eosin(HE), Serum alanine aminotransferase and aspartate aminotransferase assay kits were purchased from BioSino BioTechnology \& Science Inc.; In Suit Cell Death Detection kit(Fluorescein) were purchased from Roche; AntiBax, anti-Bcl2, anti-caspase-3 were purchased from Beijing Bioss Biotechnology Co., Ltd.; SABC immunohistochemical kit was purchased from BOSTER Bioengineering Co., Ltd.; Diaminobenzidine(DAB) was purchased from Thermo Scientific.

\subsection{Animal care and use}

Male wistar rats (specefic pathogen free, SPF) weighing about 240-280 $\mathrm{g}$ and male Kunming (KM) mice (SPF) weighing about 18-22g were purchased from Liaoning Changsheng Biotechnology Co., Ltd.; Male New Zealand white rabbits (SPF) weighting 2.0-3.0kg were purchased from Liaoning Changsheng Biotechnology Co., Ltd. Animal care and research protocols were based on the principles and guidelines adopted by the European Union Directive 2010/63/EU for animal experiments and approved by the Institutional Animal Care and Use Committee of Jilin University.

\subsection{Molecular docking}

Ligand and receptor molecular selection: CLP, D-CL is a ligand compound; The crystal structure of P2Y 12 was downloaded from the Brookhaven Protein Database(http://www.rcsb.org/pdb.com, P2Y 12 PDB ID Codes: 4NTJ). ChemBioDraw Ultra 14.0 Software was used to draw the planar structure of the ligand, transform it into a three-dimensional structure, and conduct energy minimization. AutoDock Tools1.5.4(ADT) software was used to remove ligands from macromolecular proteins, delete water, add nonpolar hydrogen and calculate point charge, set the grid of ligand molecules and receptor molecules, run AutoGrid4.2 to generate necessary graphics files, and run AutoDock4.2 to conduct molecular docking calculation experiments.

\subsection{Pharmacodynamic research}

Wistar rats were given $0.5 \% \mathrm{CMC}$ (as the negative control group, the same as below) $\mathrm{DD}-\mathrm{CL}(5 \mathrm{mg} / \mathrm{kg}$, $10 \mathrm{mg} / \mathrm{kg}, 20 \mathrm{mg} / \mathrm{kg})$ or CLP $(10 \mathrm{mg} / \mathrm{kg}$, equivalent to clinical $75 \mathrm{mg} / \mathrm{kg}$ dose $)$, after $4 \mathrm{~h}$ rats were anaesthetized with chloral hydrate( $3 \mathrm{mg} / \mathrm{kg}$, i.p.), blood was drawn from the abdominal aorta into a plastic syringe. For rabbits, CLP or D-CL(Loading dose: $20 \mathrm{mg} / \mathrm{kg}$ followed by maintenance dose of $5 \mathrm{mg} / \mathrm{kg}$ once daily in the morning for 6 days, equivalent to clinical loading dose: $300 \mathrm{mg} / \mathrm{kg}$, maintenance dose $75 \mathrm{mg} / \mathrm{kg}$ ), $0.5 \% \mathrm{CMC}$ was administered continuously by gavage for 7 days as a negative control. After anesthesia, blood samples were collected from auricle veins at $0 \mathrm{~h}, 4 \mathrm{~h}, 8 \mathrm{~h}, 12 \mathrm{~h}, 16 \mathrm{~h}$ and $24 \mathrm{~h}$ on the 1 st, $3 \mathrm{rd}$, 5th and 7 th days after administration, $3.8 \%\left(\mathrm{wv}^{-1}\right)$ trisodium citrate (1: 9 volumes of blood) as an anticoagulant. 
Determination of platelet aggregation by light transmission aggregometry ${ }^{[21]}: 2.0 \mathrm{~mL}$ anticoagulated blood (3.8\%(wv-1) trisodium citrate as an anticoagulant) was centrifuged at $1,000 \mathrm{rpm} / \mathrm{min}$ for $5 \mathrm{~min}$ at a room temperature in an LDZ5-2 low-speed auto-equilibrium centrifuge (Beijing Medical Centrifuge Factory, Beijing, China) to obtain platelet-rich plasma(PRP), platelet-poor plasma (PPP) was obtained by centrifugation of the remaining blood at $3,000 \mathrm{rpm} / \mathrm{min}$ for $10 \mathrm{~min}$. The aggregation rate was measured by AG800 automatic platelet aggregation device (Techlink Biomedical Technology Co., Ltd., China) after stimulation with $5 \mu \mathrm{mol}$ ADP.

Antithrombotic activity in vitro: according to the Chandler method ${ }^{[22]}$, antithrombotic activity was investigated using a thrombosis instrument in vitro. $1.5 \mathrm{~mL}$ whole blood was collected in a silicone tube, and then the tube was placed in a pre-warmed LYB-F/S thrombosis instrument (Beijing Prisheng Instrument Co. LTD, China), after $15 \mathrm{~min}\left(3.7 \mathrm{rpm} / \mathrm{min}, 37^{\circ} \mathrm{C}\right)$ of rotation, the thrombus was carefully pulled out from the tube. The wet thrombus weight and length were immediately determined. After weighing, the thrombus was put into an XSN type thrombus constant-temperature oven(Wuxi County electronic instrument no. 2 factory, China), baked at $60^{\circ} \mathrm{C}$ for $30 \mathrm{~min}$ and weighed. At this time, the weight was the dry weight of the thrombus.

\subsection{Pharmacokinetic research}

KM mice were given orally as follows: CLP or D-CL(Loading dose: $60 \mathrm{mg} / \mathrm{kg}$ followed by maintenance dose of $15 \mathrm{mg} / \mathrm{kg}$ once daily in the morning for 6 days, equivalent to clinical loading dose: $300 \mathrm{mg} / \mathrm{kg}$, maintenance dose $75 \mathrm{mg} / \mathrm{kg}$ ), 0.5\%CMC was administered continuously by gavage for 7 days as a negative control. One hour after administration on the seventh day, mice were anesthetized with pentobarbital $(40 \mathrm{mg} / \mathrm{kg}$, i.p.), $0.5 \mathrm{~mL}$ of blood was taken from the eyeball to measure the concentration of active metabolites, and $0.6-0.8 \mathrm{~g}$ of liver was taken to analyze the activity of CYP450 enzymes.

Determination of active metabolites: $0.5 \mathrm{~mL}$ blood was immediately added into a centrifuge tube containing EDTA-2Na and 40 $\mathrm{LLMPB}$, mixed upside down for 5 times, incubated in dark for $10 \mathrm{~min}$, centrifuged at $13,000 \mathrm{rpm} / \mathrm{min} 4^{\circ} \mathrm{C}$ for $5 \mathrm{~min}$, and the derived plasma was taken and stored at $-80^{\circ} \mathrm{Cfor}$ detection. The content of active metabolites in plasma was determined by HPLC-MS/MS as described previously ${ }^{[23]}$ (Agilent1100 High performance liquid chromatography, AB SCIEX Q-trap 5500).

Determination of CYP450 enzymes activity: the liver(0.6-0.8g) was immediately washed in $0.25 \mathrm{~mol} / \mathrm{L}$ of cold sucrose solution(PH7.4), cut into pieces with scissors on the ice and homogenized with tissue homogenizer(Beijing Grinder Instrument Co.Ltd. GT100X). Homogenate was centrifuged at 13,000 $\mathrm{rpm} / \mathrm{min} 4^{\circ} \mathrm{C}$ for $20 \mathrm{~min}$. The supernatant was collected and additionally centrifuged at $100,000 \mathrm{~g}$ at $4^{\circ} \mathrm{C}$ for $60 \mathrm{~min}$ (Beckman Coulter Optima MAX-XP Benchtop Ultracentrifuge). Sedimented liver microsomes were resuspended in cold potassium pyrophosphate solution(PH7.4), and centrifuged at $100,000 \mathrm{~g} 4^{\circ} \mathrm{C}$ for $60 \mathrm{~min}$, sedimented liver microsomes were resuspended in cold Tris-HCL(PH7.4), stored separately at $-80^{\circ} \mathrm{C}$ for detection. The concentration of liver microsomes was analyzed by BCA method, 
the activity of cytochrome P450(CYP450) enzymes was determined by Cocktail method ${ }^{[24-25]}$, phenacetin, bupropion, paclitaxel, tolbutamide, S-mephenytoin, dextromethorphan and testosterone were used as probe substrates for CYP1A2(mice:CYP1a2), CYP2B6(mice:CYP2b9), CYP2C8(CYP2c29), CYP2C9(mice:CYP2c37), CYP2C19(mice:CYP2c39/40/44), CYP2D6(mice:CYP2d6) and CYP3A4(mice:CYP3a11) respectively.

\subsection{Blood biochemical test}

Wistar rats were given $0.5 \% \mathrm{CMC} D-\mathrm{CL}(5 \mathrm{mg} / \mathrm{kg}, 10 \mathrm{mg} / \mathrm{kg}, 20 \mathrm{mg} / \mathrm{kg})$ or $\mathrm{CLP}(10 \mathrm{mg} / \mathrm{kg})$, after $4 \mathrm{~h}$ rats were anaesthetized with chloral hydrate ( $3 \mathrm{mg} / \mathrm{kg}$, i.p.), blood was drawn from the abdominal aorta into a plastic syringe containing $3.8 \%\left(\mathrm{wv}^{-1}\right)$ trisodium citrate (1:9 volumes of blood) as an anticoagulant.

Blood routine, PT, APTT determination: $2.0 \mathrm{~mL}$ anticoagulant whole blood was collected and routine blood tests were performed using POCH-100ivd automatic blood cell analyzer (SYSMEX, Japan). The remaining anticoagulant blood was centrifuged at room temperature at $3,000 \mathrm{rpm} / \mathrm{min}$ for $10 \mathrm{~min}$ to obtain platelet poor plasma. Prothrombin time(PT) and activated partialthromboplastin time(APTT) were measured in accordance with the methods provided by the biological reagents provider for an automatic blood coagulation analyzer(SEKISUIMEDICALCO., LTD) ${ }^{[26]}$.

Determination of bleeding time in mice: The bleeding time was measured as described previously[27]. Briefly, the test drugs $(0.5 \% \mathrm{CMC} \otimes 7.5 \mathrm{mg} / \mathrm{kg}, 15 \mathrm{mg} / \mathrm{kg}, 30 \mathrm{mg} / \mathrm{kg}$ D-CL or $15 \mathrm{mg} / \mathrm{kg}$ CLP) were orally administered $4 \mathrm{~h}$ before the tail transection. Under anaesthesia with pentobarbital ( $40 \mathrm{mg} / \mathrm{kg}$, i.p.), the mice tail was transected at $3 \mathrm{~mm}$ from the tip by a scalpel, the blood was sucked with a filter paper every 30 s until the blood was naturally stop. Bleeding time was assessed as the time from the tail transection to the termination of blood flow. For statistical analysis, bleeding time over 3600 s were regarded as 3600 s.

\subsection{Determination of transaminase activity}

Serum alanine aminotransferase (ALT) and aspartate aminotransferase (AST) are two important liver enzymes circulating in the blood, which has been commonly included in liver function tests ${ }^{[28]}$. After 7 days of continuous administration(CLP or D-CL Loading dose: $30 \mathrm{mg} / \mathrm{kg}, 60 \mathrm{mg} / \mathrm{kg}$ or $120 \mathrm{mg} / \mathrm{kg}$ followed by maintenance dose of $7.5 \mathrm{mg} / \mathrm{kg}, 15 \mathrm{mg} / \mathrm{kg}$ or $30 \mathrm{mg} / \mathrm{kg}$ once daily in the morning for 6 days), $0.5 \% \mathrm{CMC}$ was administered continuously by gavage for 7 days as a negative control), mice were anesthetized with pentobarbital (40 mg/kg, i.p.), sacrificed with cervical dislocation and their hearts exposed. $0.7 \mathrm{~mL}$ of blood was taken from the eyeball to analyze the activity of transaminase, and the left liver was taken for Hematoxylin and eosin(HE) staining to observe the pathological changes of liver tissue. The blood was placed at room temperature for $4 \mathrm{~h}$, centrifuged at $2,500 \mathrm{rpm} / \mathrm{min}$ for $20 \mathrm{~min}$, and the supernatant was taken and stored in a refrigerator at $-20^{\circ} \mathrm{C}$ for testing. CA400 automatic biochemical analyzer(Furuno, Japan) was used to measure transaminase in strict accordance with AST and ALT kit instructions. 


\subsection{HE staining observed the histomorphology of liver}

HE staining can better display the tissue structure and cell morphology, and can be used to observe and describe the morphology of normal and pathological tissues ${ }^{[29]}$. The left liver leaf of mice extracted in 2.10 was immediately washed with normal saline, formalin-fixed, paraffin-embedded sections(Leica EG1150H, RM2245, Germany) of livers from the different experiments were stained with hematoxylin and eosin, and images were obtained using a microscope (OLYMPUS BX51, Japan).

\subsection{Terminal deoxynucleotidyl transferase dUTP nick end labeling (TUNEL) staining}

In the process of apoptosis, cells activate some endonuclease enzymes which cut the genomic DNA between nucleosomes. When the genomic DNA is broken, the exposed $3^{\prime}-\mathrm{OH}$ can be treated with green fluorescent probe fluorescein (FITC) labeled dUTP under the catalysis of terminal deoxynucleotide

transferase and thus be examined by fluorescence microscope ${ }^{[30-31]}$. After 7 days of continuous administration(CLP or D-CL loading dose: $120 \mathrm{mg} / \mathrm{kg}$ followed by maintenance dose of $30 \mathrm{mg} / \mathrm{kg}$ once daily in the morning for 6 days, $0.5 \% \mathrm{CMC}$ as a negative control), mice were sacrificed with cervical dislocation and their hearts exposed. Carefully thrust the syringe full of normal saline into the left ventricle, open the right ventricle to drain the fluid, and slowly inject normal saline into the heart. When most of the blood flows out, remove the syringe full of normal saline and insert the syringe full of formalin fixation into the same position, and slowly inject $20 \mathrm{ml}$ of the fixed solution. After the perfusion, the liver was taken out and put into a glass bottle containing formalin. The left lobe of the liver was used for apoptosis detection, and the right lobe of the liver was used for immunohistochemical detection of apoptosis-related proteins. The paraffin sections of liver tissues were made in the same manner as 2.11, apoptosis was determined in strict accordance with the In Suit Cell Death Detection kit(Fluorescein) instructions, and green fluorescence was TUNEL stained positive cells.

\subsection{Detection of apoptosis-related protein expression in liver tissue}

B-cell lymphoma-2(Bcl-2) and Bcl-2 Associated X Protein(Bax) coexist in mitochondria and regulate cell apoptosis by forming dimers ${ }^{[32-33]}$. Caspase-3 plays a particularly important role in the Caspase family, which is called "death protein". Both the death receptor pathway and the mitochondrial pathway caused by apoptosis can activate caspase- 3 and thus induce cell apoptosis ${ }^{[34]}$. The paraffin sections of liver tissues were made in the same manner as 2.11, dewaxing was performed, incubation with $3 \% \mathrm{H}_{2} \mathrm{O}_{2}$, antigen repair, dripping of primary antibody working solution, biotin-labeled secondary antibody working solution, dripping of SABC and DAB for color development, re-staining, dehydration, transparent and sealing of the sections, and finally the sections were observed and photographed under a microscope(OLYPUS BX51, Japan). Three fields were randomly selected from each section, and the average optical density (AOD) of positive cells in each group was measured with BI-2000 
immunohistochemical analysis software. After DAB staining, the positive expressions of Bcl-2, Bax and caspase-3 in liver tissues were brown, and AOD values were measured accordingly. The expression level of the target factor was directly proportional to the AOD value of the image, so as to analyze the expression levels of Bcl-2, Bax and caspase-3 in liver tissues.

\subsection{Data analysis}

Molecular docking was based on the combination of free energy ( $\Delta$ Gbind) and estimated inhibition constant $(\mathrm{Ki})$. The $\Delta \mathrm{G}$ and $\mathrm{Ki}$ values of each compound and each docking target protein were compared to explore the binding of the drug to the target protein.

Data were analyzed using GraphPad Prism 7 software (GraphPad Software) and are presented as mean \pm SD. Statistical differences between drug treatment groups and vehicle were analyzed by one-way ANOVA followed by Dunnett's multiple comparison test. Results were considered significant at $* P<0.05$, $\star \star P<0.01, * \star \star P<0.001$.

\section{Results}

\subsection{Molecular docking showed that D-CL was more likely to bind to $\mathrm{P}_{2} \mathrm{Y}_{12}$ receptor}

AutoDock was used todock the active metabolites of CLP and D-CL with $P 2 \mathrm{Y}_{12}$ receptor respectively. The results are shown in Fig.1B-E, it can be seen that after deuterium generation, the binding energy and inhibition constant of D-CL with $\mathrm{P}_{2} \mathrm{Y}_{12}$ receptor become smaller $\left(-5.62 \mathrm{kcal} \cdot \mathrm{mol}^{-1} \mathrm{VS}-5.7 \mathrm{kcal} \cdot \mathrm{mol}^{-1}\right.$, $75.35 \mu \mathrm{mol} \cdot \mathrm{L}^{-1} \mathrm{VS} 66.88 \mu \mathrm{mol} \cdot \mathrm{L}^{-1}$ ), and the number of hydrogen bonds formed increases(1 VS 2), indicating $\mathrm{D}-\mathrm{CL}$ is more likely to bind to $\mathrm{P} 2 \mathrm{Y}_{12}$ receptor, and the binding is more stable.

\subsection{Platelet aggregation is dose-dependently inhibited by $D-C L$, and the inhibition effect of D-CL on platelet aggregation is more stable}

The effect of D-CL on platelet aggregation was determined by light transmission aggregometry method. Fig.2A shows the platelet aggregation rate measured $4 \mathrm{~h}$ after administration of the drug in rats. It can be seen from the figure that D-CL inhibits platelet aggregation in a dose-dependent manner, and the inhibitory effect of $10 \mathrm{mg} / \mathrm{kg}$ D-CL on platelet aggregation is equivalent to that of CLP; Fig.2E shows the aggregation rate of rabbits at different time points on day $1,3,5$ and 7 , compared with CMC, D-CL and CLP significantly inhibited platelet aggregation, however, the inhibitory effect of D-CL on platelet aggregation was significantly stronger than CLP at $12 \mathrm{~h}$ to $24 \mathrm{~h}$ after each administration. In other words, compared with CLP, D-CL exhibited a marked inhibition of ADP-induced platelet aggregation in PRP with a long duration of action. 


\subsection{D-CL inhibited thrombosis in a dose-dependent manner}

The antithrombotic effect of D-CL was evaluated by establishing in vitro thrombotic model. The results are shown in Fig.2B, C, D, compared with CMC, D-CL significantly reduced the weight and shortened the length in a dose-dependent manner. The inhibitory effect of $10 \mathrm{mg} / \mathrm{kg} \mathrm{D-CL}$ on thrombosis was consistent with that of CLP.

\subsection{The concentration of active metabolites in D-CL plasma increased}

The only difference between D-CL and CLP is 7-methyl formate methyl hydrogen is deuterium generation, other characteristics including metabolic pathways are consistent, the difference between the two active metabolite is lies in whether methyl deuterium generation, according to Fig.3A methyl deuterium generation can obviously improve the bioavailability of the CLP, produce more of the active metabolite, which is also consistent with the results of molecular docking and platelet aggregation.

\subsection{D-CL can reduce the inhibition of CYP450 enzymes activity}

In vivo, CLP requires two steps of CYP450 enzymes metabolism to produce active metabolites and thus play an anti-platelet role. Therefore, is the increase of D-CL active metabolites related to the activity of CYP450 enzymes? In this experiment, liver microsomes of mice were extracted and the activity of CYP450 enzymes in liver microsomes was analyzed by HPLC-MS/MS. The results are shown in Fig.3B-I, compared with CMC, D-Cl and CLP had no significant effect on the concentration of CYP450 and the activities of CYP1A2, CYP2C8 and CYP2B6; CLP significantly reduced the activity of CYP2B6, CYP2C9 and CYP2C19, while D-Cl significantly weakened the inhibition of CYP2B6, CYP2C9 and CYP2C19, and even increased the activity of CYP2C9; Both D-Cl and CLP could significantly increase the activity of CYP3A4.

\subsection{D-CL can prolong PT, but has no significant effect on APTT and blood routine}

Using POCH-100ivd automatic blood cell analyzer (SYSMEX, Japan) for blood routine examination. The results are shown in Fig.4, compared with CMC and CLP, D-CL had no significant effect on blood routine, indicating that deuterium introduction was not harmful to the blood system.

The experimental results of PT and APTT are shown in Fig.5A and Fig.5B, D-CL significantly prolonged PT in a dose-dependent manner, and the effect of $10 \mathrm{mg} / \mathrm{kg}$ D-CL on PT was similar to that of CLP. However, neither D-CL nor CLP had a significant effect on APTT. 


\subsection{In mice, compared with CLP, D-CL did not prolong the bleeding time}

It is necessary to rationally evaluate the bleeding risk of antithrombotic drugs. Compared with CMC, CLP and D-CL both prolong the bleeding time. However, compared with CLP, D-CL showed no tendency to prolong bleeding time. PT is an important indicator for the examination of exogenous coagulation system function and an important monitoring indicator for clinical anticoagulation therapy. In this study, D-CL was evaluated by combining PT and bleeding time, and the results showed that compared with CLP, D-CL had no tendency to increase the risk of bleeding.

\subsection{D-CL had no significant effect on transaminase activity}

ALT and AST are present in liver cells. After continuous intragastric administration for 7 days, the activity of transaminase in serum of mice was measured. The results(Fig.6A, B) showed that compared with the CMC or CLP group, D-CL did not cause the increase of transaminase level, indicating that the introduction of deuterium had no significant effect on liver function.

\subsection{Histology studies demonstrate that D-CL had no significant damage to liver tissue}

HE staining is based on the different affinity of tissues or cells to hematoxylin, and the nucleus and cytoplasm will show different colors, showing the general morphological and structural characteristics of tissues or cell components and lesions. HE staining(Fig.7) showed that the cell morphology and structure of each administration group were normal, with uniform distribution of nuclei and regular radial arrangement of cords without obvious pathological changes. Therefore, it was known that D-CL would not cause pathological damage to the liver.

\subsection{D-CL induced weaker hepatocyte apoptosis than clopidogrel}

The In Suit Cell Death Detection Kit (Fluorescein) was used to detect the apoptosis of mice hepatocytes. The results were shown in Fig.7, compared with CMC, D-CL and CLP both increased the apoptosis of hepatocytes, but compared with CLP, D-CL had less effect on the apoptosis of hepatocytes. Next, the expression levels of $\mathrm{Bcl}-2$, Bax and caspase-3 in mice liver tissues were determined to further analyze the effect of drugs on the apoptosis of liver cells.

\subsection{D-CL may inhibit hepatocyte apoptosis by inhibiting the expression of caspase-3 protein}


The effects of D-CL on the expression of $\mathrm{Bcl}-2, \mathrm{Bax}$ and caspase- 3 were determined by immunohistochemistry, the results(Fig.6C-F, Fig.7) showed that: compared with CMC, D-CL and CLP had no significant effect on the expression of $\mathrm{Bcl}-2$ in mice liver tissues, the expression levels of Bax and caspase-3 were significantly increased, and the levels of Bcl-2/Bax were significantly decreased, indicating that D-CL and CLP could cause the increased of hepatocyte apoptosis. However, compared with CLP, D-CL had no significant effect on the expression of Bcl-2 and Bcl-2/Bax, while the expression levels of Bax and caspase- 3 were significantly decreased, this suggests that $D-C L$ has a slightly weaker effect on hepatocyte apoptosis than CLP.

\section{Discussion}

At present, anticoagulants, antiplatelet agents and thrombolytic agents are the main clinical antithrombotic drugs, among which antiplatelet agents account for the largest market share ${ }^{[35]}$. $P 2 Y_{12}$ receptor antagonist is the most widely used antiplatelet aggregation drug ${ }^{[36]}$. However, it still have many unsatisfactory aspects, such as the individual differences of CLP and the bleeding risk of prasugrel ${ }^{[37]}$.Therefore, it is of great significance to develop more efficient and safer new thienopyridine.

Studies on the effect of deuteration on drug efficacy first began in the early 1960 s, Belleau et al ${ }^{[38]}$ found that hydrogen of tyramine and tryptamine, when replaced by deuterium, can slow down the metabolism of monoamine oxidase in rats. Elison et al ${ }^{[39]}$ found that when the $\mathrm{N}$-methylhydrogen deuterium in morphine was substituted, not only the drug effect was significantly reduced, but also the Ndemethylation rate was reduced, and the binding force to the enzyme active center was also significantly weakened. Deuterium plays an important role in pharmacology, such as reducing system clearance rate, increasing biological half-life, reducing toxic and side effects, and enhancing efficacy ${ }^{[40]}$.

In view of the above situation, our team synthesized D-CL to alleviate the deficiency of CLP in clinical application. This study aims to further study the influence of deuterium introduction on CLP.

AutoDock ${ }^{[41]}$ is one of the many protein-ligand docking programs available. In this study, Autodock4.2.1 software was used todock the active metabolites of CLP and D-CL with $P 2 Y_{12}$ receptor, respectively, and to judge the influence of deuterium on CLP at the virtual level. The results(Fig.1B-E) showed that D-CL was more stable in binding to $\mathrm{P}_{2} \mathrm{Y}_{12}$ receptor, which may have better efficacy than CLP.

CLP has attracted much attention because of its superior safety compared with prasugrel and ticagrelor, but it also has some disadvantages that cannot be ignored, such as slow onset, greater influence of gene polymorphism and drug-drug interaction, this is in part due to its reliance on CYP450 enzymes for conversion into its active metabolite ${ }^{[42]}$. After continuous 7 days of administration, the platelet aggregation rate(Fig. $2 \mathrm{E}$ ) in the D-CL group was maintained at about $20 \%-40 \%$, while the CLP fluctuated in a larger range $(20 \%-50 \%)$. That is to say, the anti-platelet aggregation effect of D-CL was significantly better than CLP 12-24h after administration, indicating that D-CL could maintain the effective therapeutic effect within $24 \mathrm{~h}$ after each administration, and this effect would bring significant benefits to patients. At 
the same time, the test results of active metabolites(Fig.3A) also indirectly indicated that D-CL has a stronger antiplatelet effect, because $\mathrm{D}-\mathrm{Cl}$ could produce more active metabolites.

As a prodrug, CLP can only generate active metabolites after two steps of CYP450 enzymes metabolism ${ }^{[43]}$. The effects of CLP and D-CL on CYP450 enzymes activity were studied, and the results(Fig.3B-I) showed that compared with CMC, CLP could significantly inhibit the activities of CYP2B6, CYP2C9 and CYP2C19, this is in agreement with previous studies ${ }^{[44]}$. CLP inhibited CYP2B6 with highest potency and CYP2C9, CYP2C19 with lower potency. However, compared with CLP, D-Cl significantly increased the activity of CYP2C9 and CYP2C19 by $40.5 \%$ and $40 \%$, respectively. As the only active enzyme in the CYP2B subfamily, CYP2B6 is an important drug metabolizing enzymes ${ }^{[45]}$, compared with CLP, D-CL increased the activity of CYP2B6 enzyme by 10.7 times. In general, the reduced inhibitory effect of D-CL on CYP2B6, CYP2C9 and CYP2C19 can greatly reduce drug-drug interactions, which is very beneficial for patients with drug combination.

In addition, blood routine, PT, APTT, beleeding time, serological tests, liver pathological biopsy, liver cell apoptosis and apoptosis-related protein were measured respectively to evaluate whether D-CL would cause adverse effects. The results showed that, compared with CLP, D-Cl had no significant effect on blood biochemical parameters and had no tendency to increase the risk of bleeding. Notably, D-CL induced a lower degree of hepatocyte apoptosis than CLP. As the main detoxification organ of the human body, the liver is also vulnerable to damage while metabolizing drugs ${ }^{[46]}$. In normal physiological processes, hepatocyte apoptosis plays an important role in protecting the liver, once the imbalance of hepatocyte apoptosis occurs, it will lead to liver injury, liver fibrosis, cirrhosis and even liver cancer ${ }^{[47]}$. This study(Fig.6C-F) showed that, compared with CLP, D-CL may reduce the apoptosis of hepatocytes by reducing the expression of Bax and Caspase-3, and thus exert a certain protective effect on hepatocytes.

\section{Conclusion}

In conclusion, the following conclusions can be drawn: a) Molecular docking technology can play an important guiding role in the design and development of $\mathrm{P}_{2} \mathrm{Y}_{12}$ receptor antagonists; b) D-CL has a stronger anti-platelet aggregation effect, a long duration of antiaggregatory action, a better effect of preventing thrombosis; C) Compared with CLP, D-CL significantly increased the activity of CYP2B6, CYP2C9 and CYP2C19, which is expected to reduce individual differences caused by CYP2C19 gene polymorphism and drug-drug interactions; d) D-CL had no significant effect on blood biochemistry and had no tendency to increase bleeding risk; e) D-CL may reduce the apoptosis of hepatocytes by reducing the expression of Bax and Caspase-3, and thus exert a certain protective effect on hepatocytes.

\section{Abbreviations}

ALT, Serum alanine aminotransferase; AOD, average optical density; APTT, activated partialthromboplastin time; AST, aspartate aminotransferase; Bcl-2, B-cell lymphoma-2; Bax, Bcl2 Associated X Protein; CLP, clopidogrel; CMC, Sodium carboxymethyl cellulose; CYP450: cytochrome 
P450; DAB, diaminobenzidine; D-CL, deuterium clopidogrel; HE, hematoxylin and eosin; HPLC-MS/MS, high performance liquid chromatography-tandem mass spectrometry; MPB, 3'-methoxyphenacyl bromide; PT, prothrombin time; SPF, specefic pathogen free; TUNEL, terminal deoxynucleotidyl transferase dUTP nick end labeling.

\section{Declarations}

\section{Funding}

This work was sponsored by the department of Science and Technology of Jilin Province(grant number 20200404131YY); The education department of Jilin Province(grant number JJKH20190009KJ); The Health and Family Planning Commission of Jilin Province(grant number 2017J055). The funding sources had no involvement in study design, collection, analysis and interpretation of data, in the writing of the report or in the decision to submit the article for publication.

\section{Author contributions}

Zhiping Xu edited the manuscript, conducted pharmacodynamics and pharmacokinetic experiments; Yujia Miao, Tianlong Wu, Liang Chen conducted pharmacodynamics experiments; Yantong Sun, Yingze Liu, Jinjin Niu, Deqi Cai conducted pharmacokinetic experiments; Mingyue Gao, Chen Chen, Xiaohua Li conducted safety experiments; Shengyang Liu did the molecular docking. Jingkai Gu synthesized D-CL, supervised the whole study; Xia Cao obtained the funding, reviewed the manuscript, and supervised the whole study. All authors approved the final version of the manuscript.

\section{Conflict of interests}

We confirm that the manuscript has been read and approved by all named authors and that there are no other persons who satisfied the criteria for authorship but are not listed. We further confirm that the order of authors listed in the manuscript has been approved by all of us.

\section{Data availability statement}

The data used to support the findings of this study are available from the corresponding author upon request.

\section{References}

1. Koupenova M, Kehrel BE, Corkrey HA, Freedman JE. Thrombosis and platelets: an update. Eur Heart J. 2017;38(11):785-791. doi:10.1093/eurheartj/ehw550 
2. Singh $P$, Harper $Y$, Oliphant CS, et al. Peripheral interventions and antiplatelet therapy: Role in current practice. World J Cardiol. 2017;9(7):583-593. doi:10.4330/wjc.v9.i7.583

3. Yu Q, Wang B, Wang Y, Dai CL. Zhonghua Xin Xue Guan Bing Za Zhi. 2019;47(6):479-485. doi:10.3760/cma.j.issn.0253-3758.2019.06.010

4. Heijnen $\mathrm{H}$, van der Sluijs P. Platelet secretory behaviour: as diverse as the granules ... or not? . J Thromb Haemost. 2015;13(12):2141-2151. doi:10.1111/jth.13147

5. Gur S, Kadowitz PJ, Hellstrom WJ. Purinergic (P2) receptor control of lower genitourinary tract function and new avenues for drug action: an overview. Curr Pharm Des. 2007;13(31):3236-3244. doi:10.2174/138161207782341277

6. Koessler J, Weber K, Koessler A, Yilmaz P, Boeck M, Kobsar A. Expression and function of purinergic receptors in platelets from apheresis-derived platelet concentrates. Blood Transfus. 2016;14(6):545551. doi:10.2450/2015.0073-15

7. Schilling U, Dingemanse J, Ufer M. Pharmacokinetics and Pharmacodynamics of Approved and Investigational P2Y12 Receptor Antagonists. Clin Pharmacokinet. 2020;59(5):545-566. doi:10.1007/s40262-020-00864-4

8. Angiolillo DJ. The evolution of antiplatelet therapy in the treatment of acute coronary syndromes: from aspirin to the present day. Drugs. 2012;72(16):2087-2116. doi:10.2165/11640880-00000000000000

9. Patti G, Micieli G, Cimminiello C, Bolognese L. The Role of Clopidogrel in 2020: A Reappraisal. Cardiovasc Ther. 2020;2020:8703627. Published 2020 Mar 16. doi:10.1155/2020/8703627

10. Knauer MJ, Diamandis EP, Hulot JS, Kim RB, So DY. Clopidogrel and CYP2C19: pharmacogenetic testing ready for clinical prime time?. Clin Chem. 2015;61(10):1235-1240. doi:10.1373/clinchem.2015.238105

11. Basov A, Fedulova L, Vasilevskaya E, Dzhimak S. Possible Mechanisms of Biological Effects Observed in Living Systems during $2 \mathrm{H} / 1 \mathrm{H}$ Isotope Fractionation and Deuterium Interactions with Other Biogenic Isotopes. Molecules. 2019;24(22):4101. Published 2019 Nov 13. doi:10.3390/molecules24224101

12. Pant HJ, Thýn J, Zitný R, Bhatt BC. Radioisotope tracer study in a sludge hygienization research irradiator (SHRI). Appl Radiat Isot. 2001;54(1):1-10. doi:10.1016/s0969-8043(00)00101-9

13. Radajewski S, Ineson P, Parekh NR, Murrell JC. Stable-isotope probing as a tool in microbial ecology. Nature. 2000;403(6770):646-649. doi:10.1038/35001054

14. Elsig J, Schmitt J, Leuenberger D, et al. Stable isotope constraints on Holocene carbon cycle changes from an Antarctic ice core. Nature. 2009;461(7263):507-510. doi:10.1038/nature08393

15. Murray MR, Benitez HH. Deuterium oxide: direct action on sympathetic ganglia isolated in culture. Science. 1967;155(3765):1021-1024. doi:10.1126/science.155.3765.1021

16. Kushner DJ, Baker A, Dunstall TG. Pharmacological uses and perspectives of heavy water and deuterated compounds. Can J Physiol Pharmacol. 1999;77(2):79-88. 
17. Di Costanzo L, Moulin M, Haertlein M, Meilleur F, Christianson DW. Expression, purification, assay, and crystal structure of perdeuterated human arginase I. Arch Biochem Biophys. 2007;465(1):82-89. doi:10.1016/j.abb.2007.04.036

18. Schmidt C. First deuterated drug approved [published correction appears in Nat Biotechnol. 2017 Nov 9;35(11):1004]. Nat Biotechnol. 2017;35(6):493-494. doi:10.1038/nbt0617-493

19. Jankovic J, Jimenez-Shahed J, Budman C, et al. Deutetrabenazine in Tics Associated with Tourette Syndrome. Tremor Other Hyperkinet Mov (N Y). 2016;6:422. Published 2016 Nov 7. doi:10.7916/D8M32W3H

20. Niemann N, Jankovic J. Treatment of Tardive Dyskinesia: A General Overview with Focus on the Vesicular Monoamine Transporter 2 Inhibitors [published correction appears in Drugs. 2018 Mar 10;:. Dosage error in article text]. Drugs. 2018;78(5):525-541. doi:10.1007/s40265-018-0874- $x$

21. BORN GV. Aggregation of blood platelets by adenosine diphosphate and its reversal. Nature. 1962;194:927-929. doi:10.1038/194927b0

22. Xin M, Ren L, Sun Y, et al. Anticoagulant and antithrombotic activities of low-molecular-weight propylene glycol alginate sodium sulfate (PSS). Eur J Med Chem. 2016;114:33-40. doi:10.1016/j.ejmech.2016.02.063

23. Xu X, Zhao X, Yang Z, et al. Significant Improvement of Metabolic Characteristics and Bioactivities of Clopidogrel and Analogs by Selective Deuteration. Molecules. 2016;21(6):704. Published 2016 May 30. doi:10.3390/molecules21060704

24. Giri P, Patel H, Srinivas NR. Use of Cocktail Probe Drugs for Indexing Cytochrome P450 Enzymes in Clinical Pharmacology Studies - Review of Case Studies. Drug Metab Lett. 2019;13(1):3-18. doi:10.2174/1872312812666181119154734

25. Kwon M, Jeon JH, Choi MK, Song IS. The Development and Validation of a Novel "Dual Cocktail" Probe for Cytochrome P450s and Transporter Functions to Evaluate Pharmacokinetic Drug-Drug and Herb-Drug Interactions. Pharmaceutics. 2020;12(10):938. Published 2020 Sep 30. doi:10.3390/pharmaceutics12100938

26. Denessen EJS, Jeurissen MLJ, Pereboom RMTA, Verhezen PWM, Henskens YMC. Determining the maximal storage time of centrifuged citrated samples for performing add-on routine coagulation tests. Thromb Res. 2020;196:54-62. doi:10.1016/j.thromres.2020.08.003

27. Xu Z, Gu J, Gao M, et al. Study on antiplatelet effect of a new thiophenopyridine platelets P2Y12 receptor antagonist DV-127. Thromb Res. 2018;170:192-199. doi:10.1016/j.thromres.2018.08.022

28. Chen SL, Li JP, Li LF, Zeng T, He X. Elevated Preoperative Serum Alanine Aminotransferase/Aspartate Aminotransferase (ALT/AST) Ratio Is Associated with Better Prognosis in Patients Undergoing Curative Treatment for Gastric Adenocarcinoma. Int J Mol Sci. 2016;17(6):911. Published 2016 Jun 9. doi:10.3390/ijms17060911

29. Nagappan A, Kim JH, Jung DY, Jung MH. Cryptotanshinone from the Salvia miltiorrhiza Bunge Attenuates Ethanol-Induced Liver Injury by Activation of AMPK/SIRT1 and Nrf2 Signaling Pathways. Int J Mol Sci. 2019;21(1):265. Published 2019 Dec 30. doi:10.3390/ijms21010265 
30. Majtnerová P, Roušar T. An overview of apoptosis assays detecting DNA fragmentation. Mol Biol Rep. 2018;45(5):1469-1478. doi:10.1007/s11033-018-4258-9

31. Najimi M, Smets F, Sokal E. Hepatocyte apoptosis. Methods Mol Biol. 2009;481:59-74. doi:10.1007/978-1-59745-201-4_6

32. Karavias DD, Tsamandas AC, Tepetes K, et al. BCL-2 and BAX expression and cell proliferation, after partial hepatectomy with and without ischemia, on cholestatic liver in rats: an experimental study. $J$ Surg Res. 2003;110(2):399-408. doi:10.1016/s0022-4804(03)00003-9

33. Moldoveanu T, Czabotar PE. BAX, BAK, and BOK: A Coming of Age for the BCL-2 Family Effector Proteins. Cold Spring Harb Perspect Biol. 2020;12(4):a036319. Published 2020 Apr 1. doi:10.1101/cshperspect.a036319

34. Geng Y, Hernández Villanueva A, Oun A, et al. Protective effect of metformin against palmitateinduced hepatic cell death. Biochim Biophys Acta Mol Basis Dis. 2020;1866(3):165621. doi:10.1016/j.bbadis.2019.165621

35. Schussheim AE, Fuster V. Thrombosis, antithrombotic agents, and the antithrombotic approach in cardiac disease. Prog Cardiovasc Dis. 1997;40(3):205-238. doi:10.1016/s0033-0620(97)80035-7

36. Wijeyeratne YD, Heptinstall S. Anti-platelet therapy: ADP receptor antagonists. Br J Clin Pharmacol. 2011;72(4):647-657. doi:10.1111/j.1365-2125.2011.03999.x

37. Peters BJ, Harmsze AM, ten Berg JM, et al. CYP2C19 and ABCB1 genes and individualized treatment with clopidogrel. Pharmacogenomics. 2011;12(2):141-144. doi:10.2217/pgs.10.211

38. Belleau B, Burba J, Pindell M, Reiffenstein J. Effect of Deuterium Substitution in Sympathomimetic Amines on Adrenergic Responses. Science. 1961;133(3446):102-104.

doi:10.1126/science.133.3446.102

39. ELISON C, RAPOPORT H, LAURSEN R, ELLIOTT HW. Effect of deuteration of N-CH3 group on potency and enzymatic N-demethylation of morphine. Science. 1961;134(3485):1078-1079. doi:10.1126/science.134.3485.1078

40. Gant TG. Using deuterium in drug discovery: leaving the label in the drug. $J$ Med Chem. 2014;57(9):3595-3611. doi:10.1021/jm4007998

41. Pagadala NS, Syed K, Tuszynski J. Software for molecular docking: a review. Biophys Rev. 2017;9(2):91-102. doi:10.1007/s12551-016-0247-1

42. Zanger UM, Schwab M. Cytochrome P450 enzymes in drug metabolism: regulation of gene expression, enzyme activities, and impact of genetic variation. Pharmacol Ther. 2013;138(1):103141. doi:10.1016/j.pharmthera.2012.12.007

43. Charfi R, Mzoughi K, Boughalleb M, et al. Response to clopidogrel and of the cytochrome CYP2C19 gene polymorphism. Tunis Med. 2018;96(3):209-218.

44. Richter T, Mürdter TE, Heinkele G, et al. Potent mechanism-based inhibition of human CYP2B6 by clopidogrel and ticlopidine. J Pharmacol Exp Ther. 2004;308(1):189-197.

doi:10.1124/jpet.103.056127

Page $17 / 26$ 
45. Gairolla J, Ahluwalia J, Khullar M, et al. Clopidogrel response in ischemic stroke patients: Is polymorphism or gender more important? Results of the CRISP study. J Clin Neurosci. 2020;76:8186. doi:10.1016/j.jocn.2020.04.038

46. Grant DM. Detoxification pathways in the liver. J Inherit Metab Dis. 1991;14(4):421-30. doi: 10.1007/BF01797915

47. Santra A, Maiti A, Das S, Lahiri S, Charkaborty SK, Mazumder DN. Hepatic damage caused by chronic arsenic toxicity in experimental animals. J Toxicol Clin Toxicol. 2000;38(4):395-405. doi:10.1081/clt100100949

\section{Figures}

A
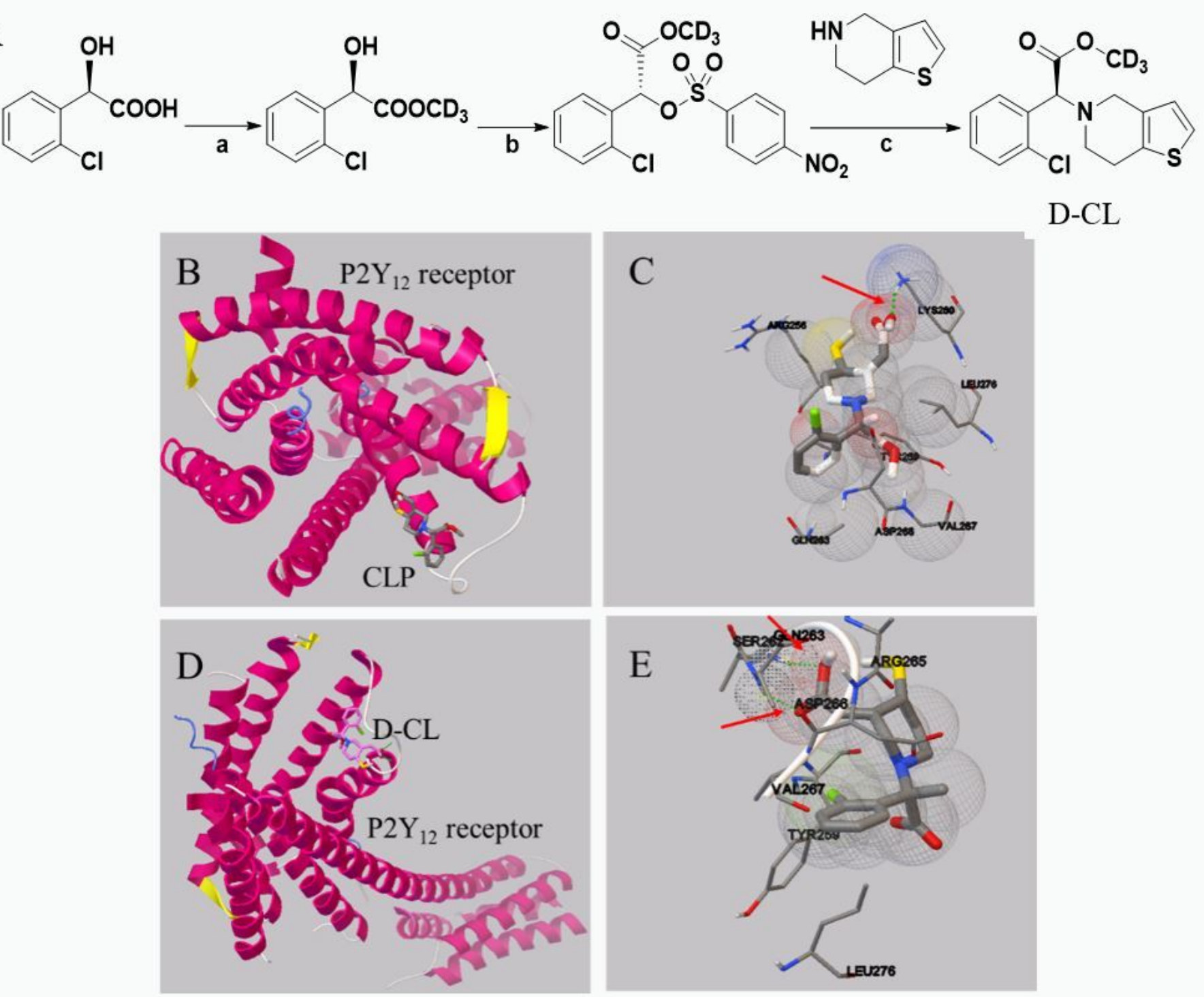

Figure 1 
A The structure of $\mathrm{D}-\mathrm{CL}$ and its synthetic route. (a) methanol, $\mathrm{HCl}$ /dioxane, reflux; (b) 4-nitrobenzene sulfonyl chloride, $\mathrm{CH} 2 \mathrm{Cl} 2$, Et3N, DMAP, $0^{\circ} \mathrm{C}$; (c) $\mathrm{K} 2 \mathrm{CO} 3$, acetone, reflux. Fig.1B, $\mathrm{C} \otimes T$ The optimal conformation of CLP active metabolites docking with P2Y12 receptor囚Fig.1D, E囚The optimal conformation of D-CL active metabolite docking with P2Y12 receptor. After deuterium generation, the binding energy and inhibition constant of D-CLP with P2Y12 receptor become smaller( $-5.62 \mathrm{kcal} \cdot \mathrm{mol}-1 \mathrm{VS}$ $-5.7 \mathrm{kcal} \cdot \mathrm{mol}-1,75.35 \mu \mathrm{mol} \cdot \mathrm{L}-1 \mathrm{VS} 66.88 \mu \mathrm{mol} \cdot \mathrm{L}-1)$, and the number of hydrogen bonds formed increases(1 VS 2), indicating that D-CL is more likely to bind to P2Y12 receptor, and the binding is more stable. Red arrow: Hydrogen bond, CLP: clopidogrel, D-CL: deuterium clopidogrel. 

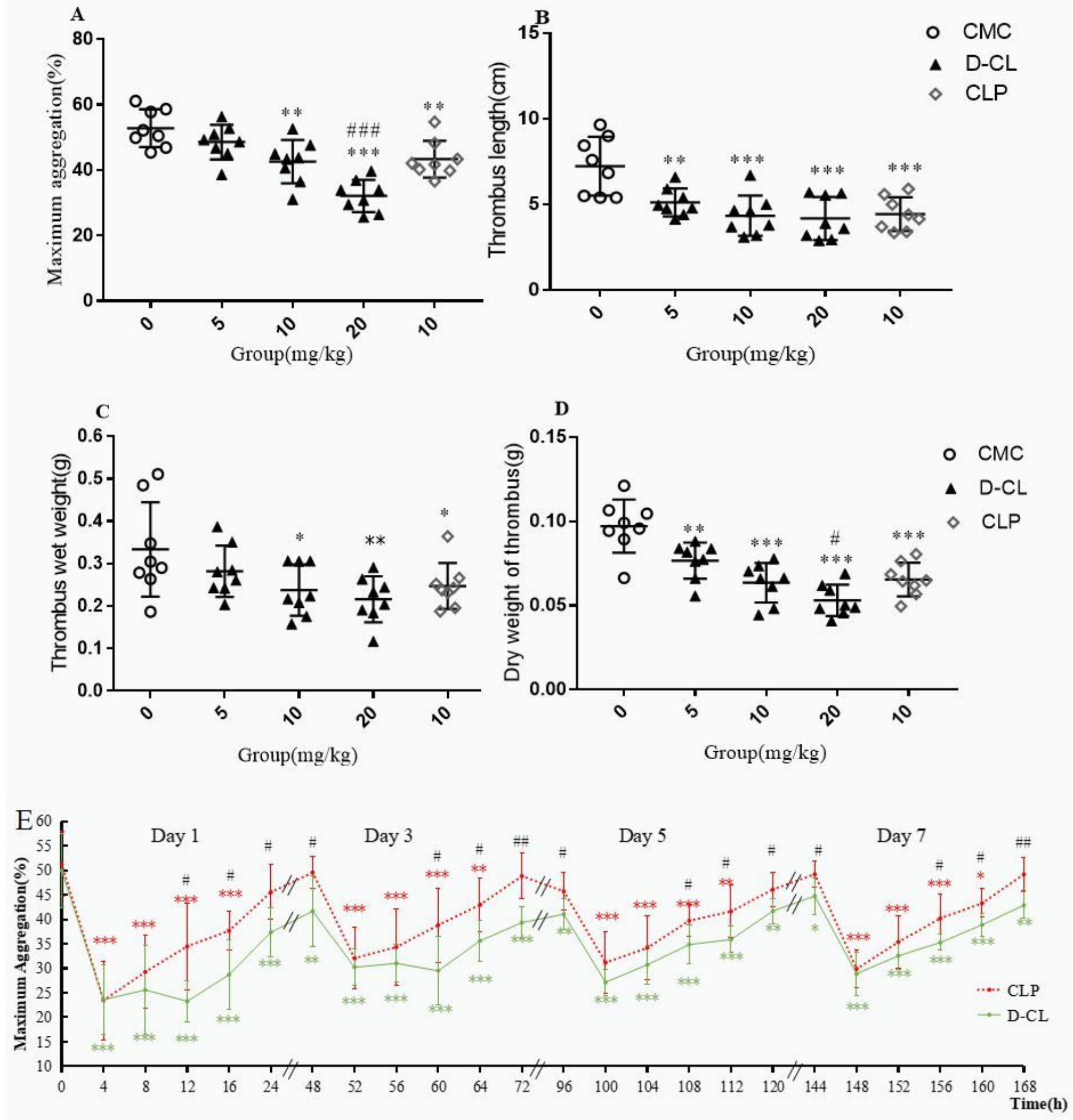

Figure 2

A The dose-effect relationship of D-Cl in inhibiting platelet aggregation in rats(n=8). Fig.2B, C, D Effect of D-CL on thrombosis. Wistar rats were given $0.5 \% \mathrm{CMC} \square \mathrm{D}-\mathrm{CL}(5 \mathrm{mg} / \mathrm{kg}, 10 \mathrm{mg} / \mathrm{kg}, 20 \mathrm{mg} / \mathrm{kg})$ or $\mathrm{CLP}(10 \mathrm{mg} / \mathrm{kg})$, after $4 \mathrm{~h}$ the platelet aggregation rate was measured, an in vitro thrombus model was established, the mean thrombus's lengths, wet weights and dry weights were expressed in $\mathrm{cm}$ and $\mathrm{g}$. Fig.2E The time-effect relationship of $\mathrm{D}-\mathrm{Cl}$ in inhibiting platelet aggregation $(n=6)$. Rabbit were dosed daily 
with D-CL or CLP for 7 consecutive days(Loading dose: $20 \mathrm{mg} / \mathrm{kg}$ followed by maintenance dose of $5 \mathrm{mg} / \mathrm{kg}$ once daily in the morning for 6 days). Results are expressed as the mean $\pm S D$, the statistical significances compared to $C M C$ are denoted by asterisks, where $* P<0.05, * \star P<0.01, * \star * P<0.001$ versus $C M C$, the statistical significances compared to CLP are denoted by aoctothorpe, where $\# P<0.05, \# \# P<0$ .01, \#\#\#P<0 .001 D-CL versus CLP, CLP: clopidogrel, D-CL: deuterium clopidogrel.
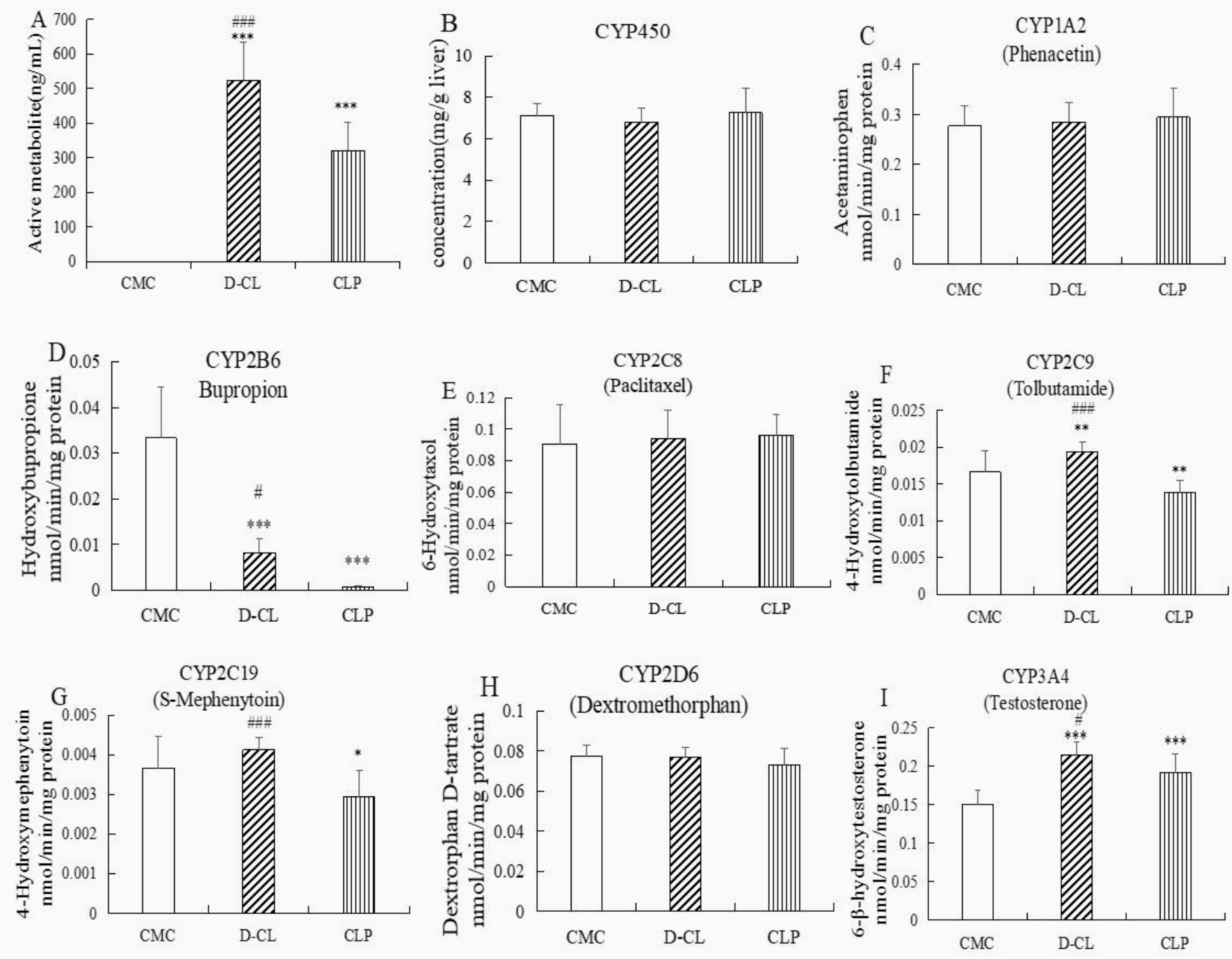

\section{Figure 3}

A Plasma concentrations of active metabolites in each administration group were compared by HPLC/MS-MS; Fig.3B-I Comparison of CYP450 content, CYP450 enzymes activity between CMC, CLP and D-CL group. Mice were dosed daily with D-CL or CLP for 7 consecutive days(Loading dose: $60 \mathrm{mg} / \mathrm{kg}$ followed by maintenance dose of $15 \mathrm{mg} / \mathrm{kg}$ once daily in the morning for 6 days), plasma active metabolite concentration, CYP450 content and CYP450 enzymes activity were determined by HPLC$M S / M S$. The results are expressed as the means $\pm S D(n=10),{ }^{*} P<0.05,{ }^{* \star} P<0.01,{ }^{* \star *} P<0.001$ vs $C M C$, $\# P<0.05$, \#\#P<0.01, \#\#\#P<0.001 D-CL vs CLP group, CLP: clopidogrel, D-CL: deuterium clopidogrel. 

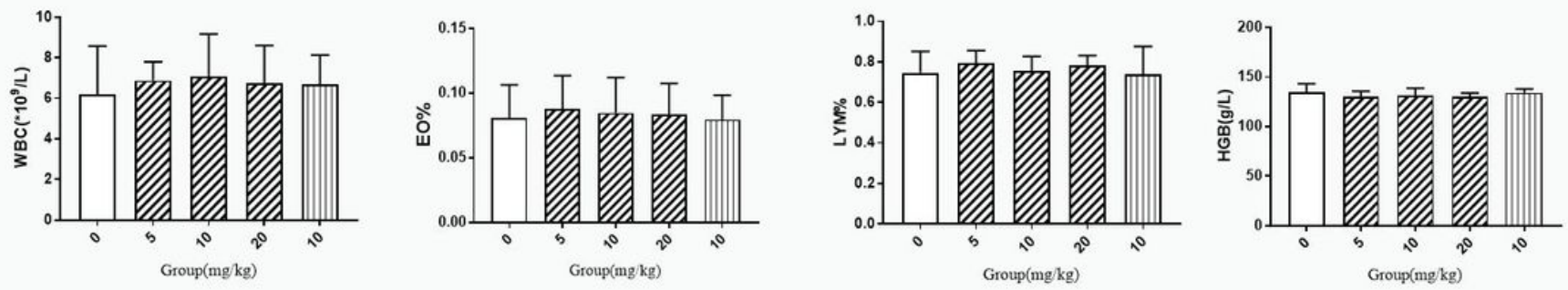

口 CMC

D.CL

四 CLP
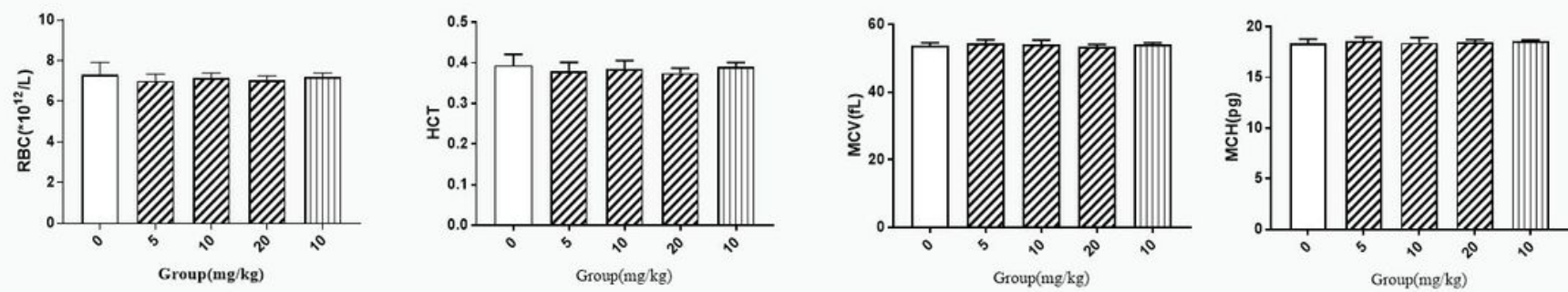

ㅁ CMC

D.CL
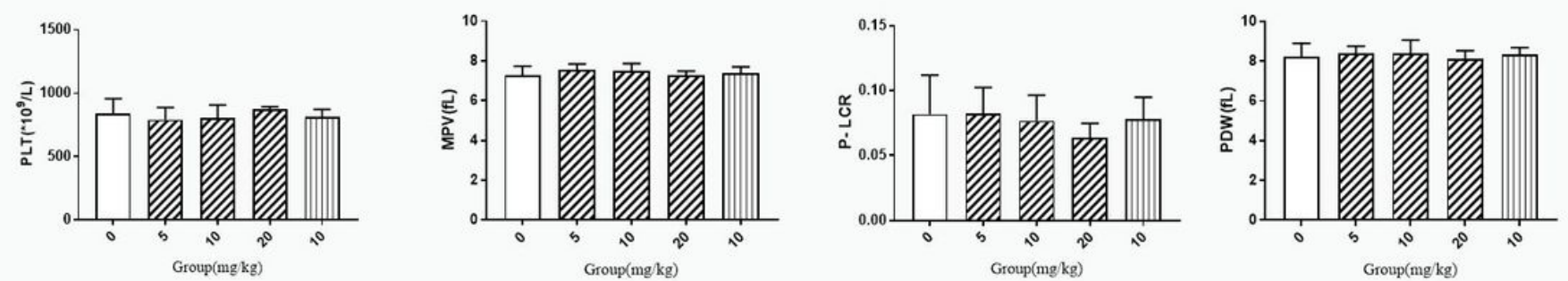

ㅁ CMC

回 CLP

Figure 4

Effect of D-CL on blood routine examination. Wistar rats were given $0.5 \% \mathrm{CMC} \square \mathrm{D}-\mathrm{CL}(5 \mathrm{mg} / \mathrm{kg}, 10 \mathrm{mg} / \mathrm{kg}$, $20 \mathrm{mg} / \mathrm{kg})$ or CLP( $10 \mathrm{mg} / \mathrm{kg}$ equivalent to clinical human $75 \mathrm{mg} / \mathrm{kg}$ dose), the results of routine blood test showed that no significant differences were noticed in the groups of rats with different doses $(P>0.05)$. Results are expressed as the mean $\pm S D(n=8)$. WBC: white blood cell; EO\%: percentage of eosinophilic cells; LYM\%: percentage of lymphocytes; HGB: hemoglobin; RBC: red blood cell; HCT: hematocrit; MCV: mean corpuscular volume; MCH: mean corpuscular hemoglobin; PLT: platelets; MPV: mean platelet volume; P-LCR: platelet-large cell rate; PDW:platelet distribution width, CLP: clopidogrel, D-CL: deuterium clopidogrel.
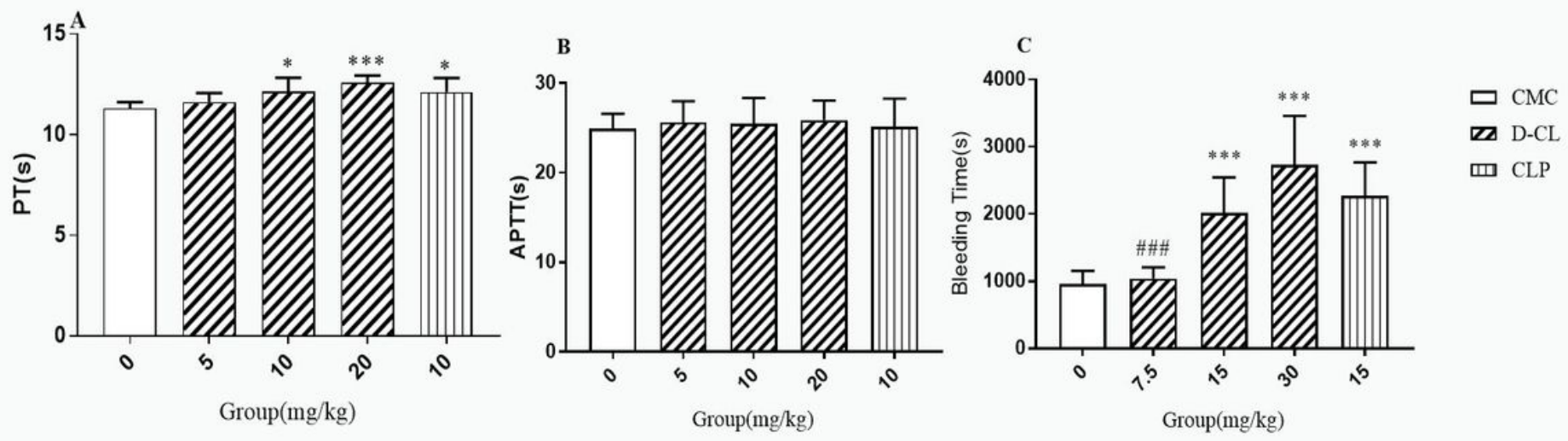


\section{Figure 5}

A, B Effect of D-CL on PT and APTT(n=8). Wistar rats were given $0.5 \% \mathrm{CMC} \square \mathrm{D}-\mathrm{CL}(5 \mathrm{mg} / \mathrm{kg}, 10 \mathrm{mg} / \mathrm{kg}$, $20 \mathrm{mg} / \mathrm{kg})$ or CLP(10 mg $/ \mathrm{kg}$ equivalent to clinical human $75 \mathrm{mg} / \mathrm{kg}$ dose $)$, PT and APTT were measured. Fig.5C Bleeding time of D-CL in mice $(\mathrm{n}=10)$. KM mice were given $0.5 \% \mathrm{CMC}, 7.5 \mathrm{mg} / \mathrm{kg}, 15 \mathrm{mg} / \mathrm{kg}$, $30 \mathrm{mg} / \mathrm{kg} \mathrm{D}-\mathrm{Cl}$ or $15 \mathrm{mg} / \mathrm{kg}$ CLP, bleeding time was detected. Results are expressed as the mean $\pm \mathrm{SD}$, ${ }^{\mathrm{P}}$

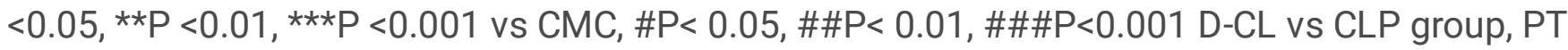
prothrombin time; APTT activated partial thromboplastin time; CLP: clopidogrel, D-CL: deuterium clopidogrel. 

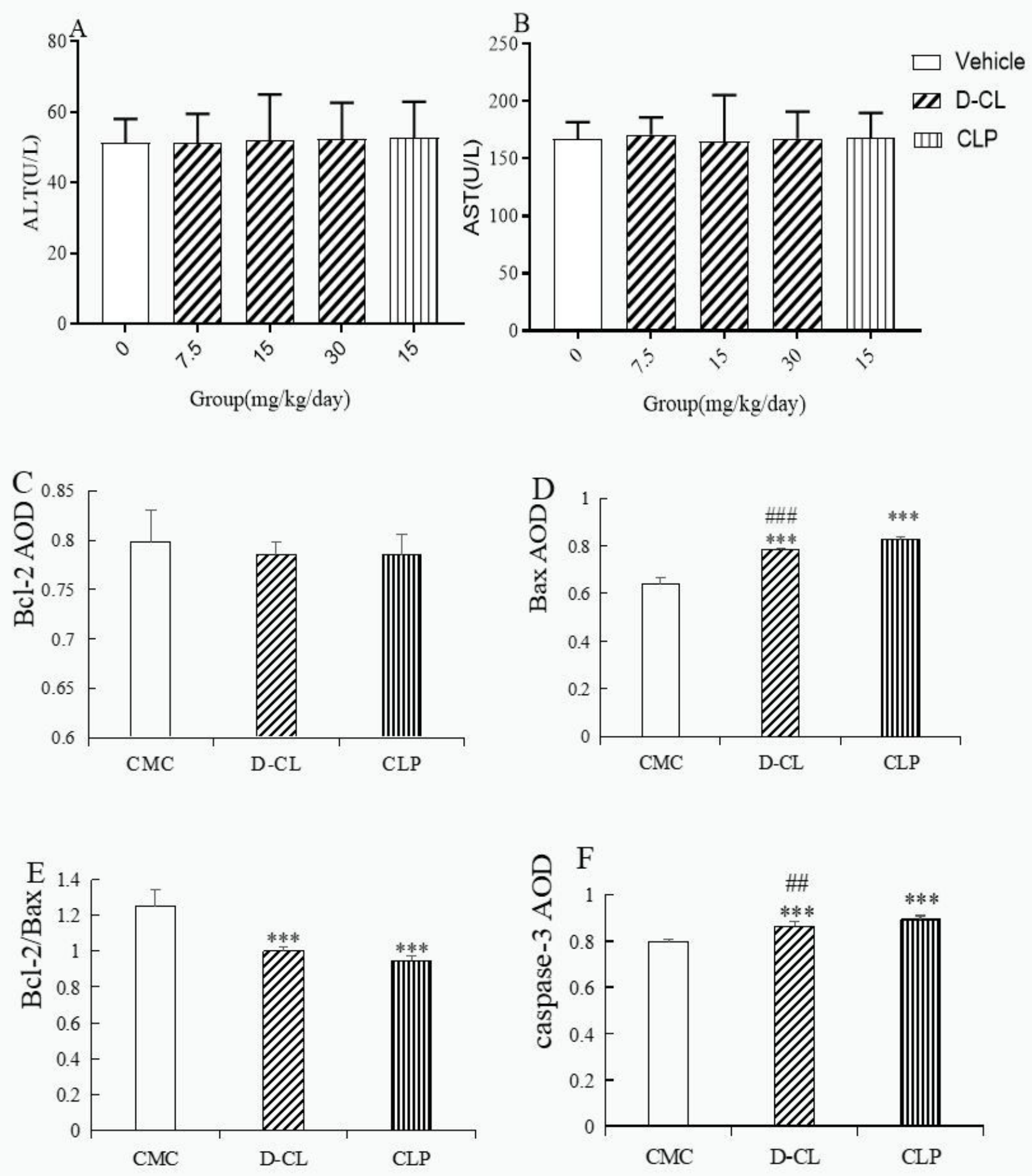

\section{Figure 6}

A, B Effect of D-CL on transaminase activity. Mice were dosed daily with D-CL or CLP for 7 consecutive days (Loading dose: $30 \mathrm{mg} / \mathrm{kg}, 60 \mathrm{mg} / \mathrm{kg}$ or $120 \mathrm{mg} / \mathrm{kg}$ followed by maintenance dose of $7.5 \mathrm{mg} / \mathrm{kg}$, $15 \mathrm{mg} / \mathrm{kg}$ or $30 \mathrm{mg} / \mathrm{kg}$ once daily in the morning for 6 days), the activity of transaminase in serum was measured( $(n=3)$. Fig.6C, D, E, F Effect of D-CL on the expression level of apoptosis related proteins in mice liver. Mice were dosed daily with D-CL or CLP for 7 consecutive days(Loading dose: $120 \mathrm{mg} / \mathrm{kg}$ 
followed by maintenance dose of $30 \mathrm{mg} / \mathrm{kg}$ once daily in the morning for 6 days), the expressions of Bcl2 , Bax and caspase-3 in mice liver were determined by immunohistochemistry $(n=3)$. Three fields were randomly selected from each section, and the AOD of positive cells in each group was measured with $\mathrm{BI}$ 2000 immunohistochemical analysis software. ${ }^{*} P<0.05$, ${ }^{*} P<0.01, * * * P<0.001$ vs $C M C, \# P<0.05$, \#\#P $<0.01$, \#\#\#P < 0.001 D-CL vs CLP group, AOD: average optical density, CLP: clopidogrel, D-CL: deuterium clopidogrel.

HE
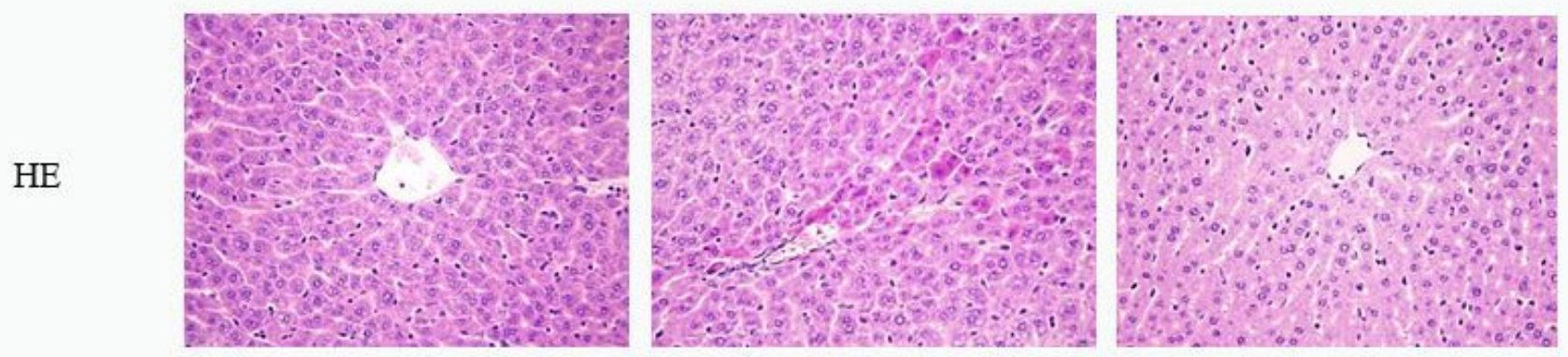

TUNEL
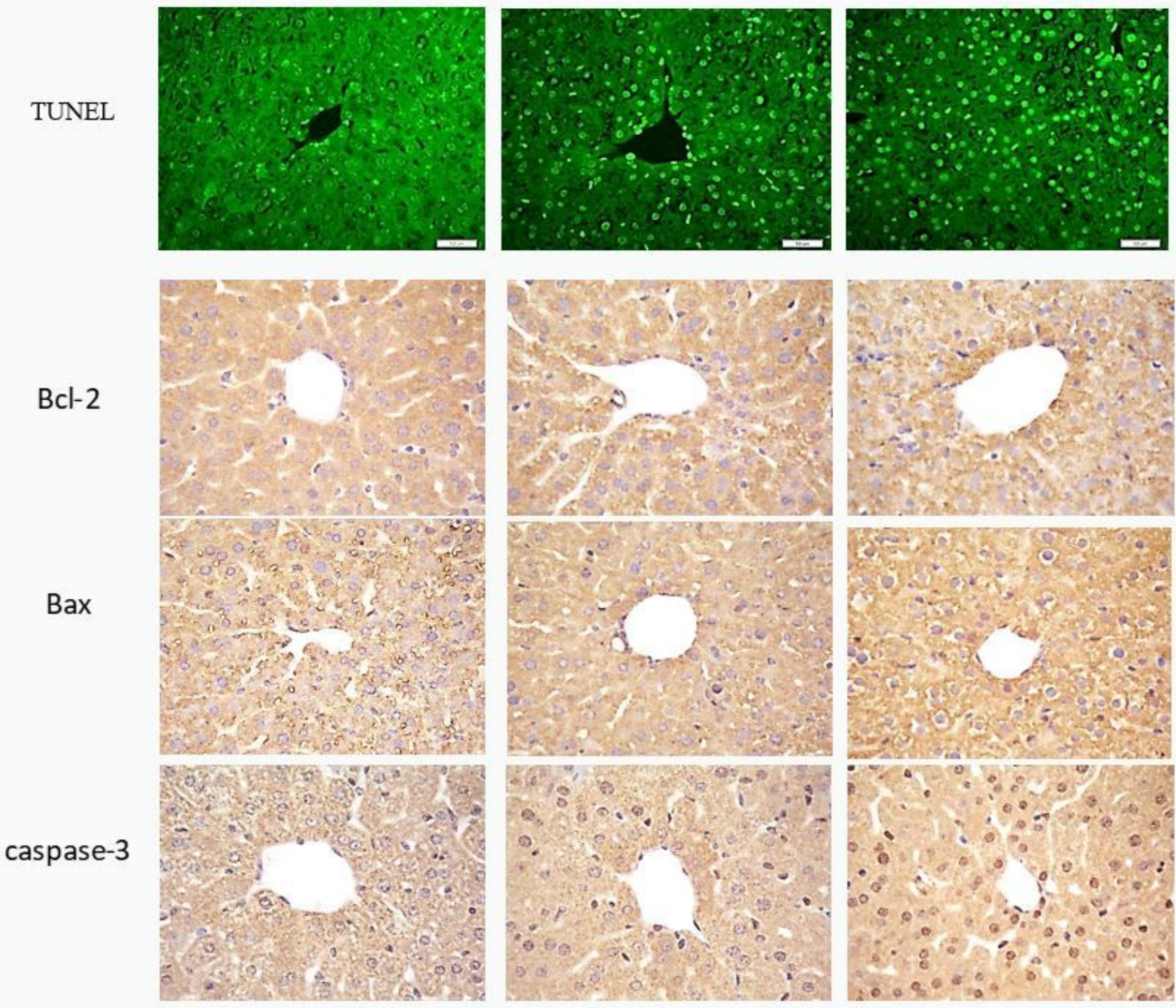

$\mathrm{CMC}$
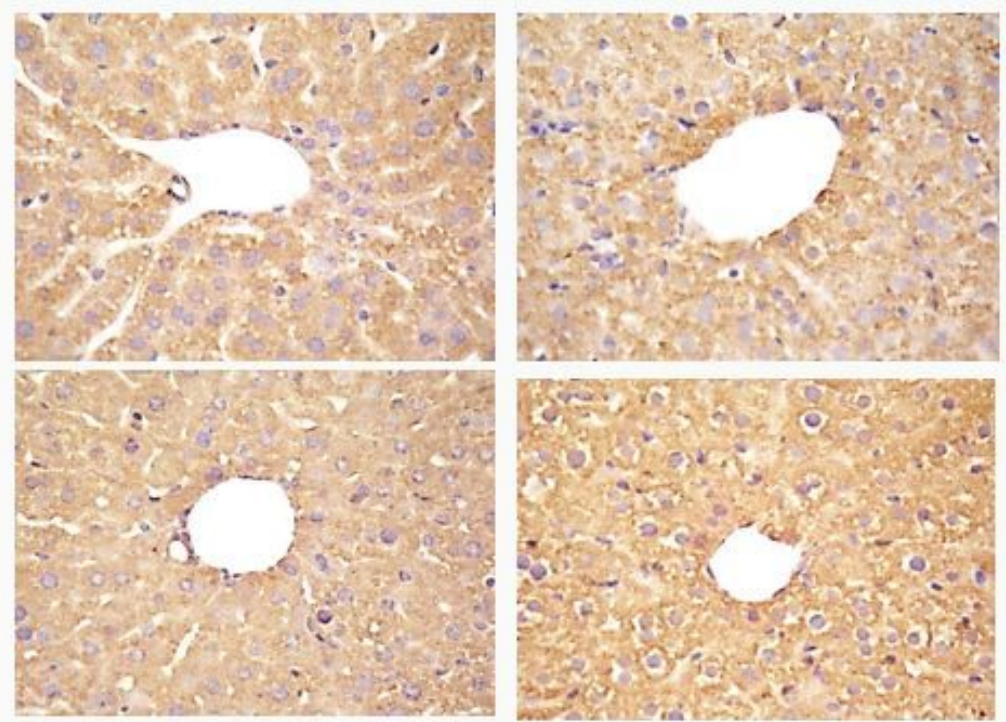

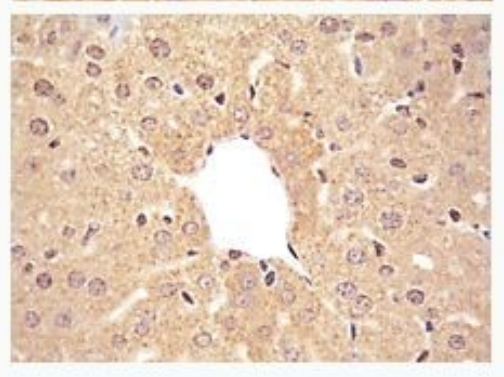

D-CL
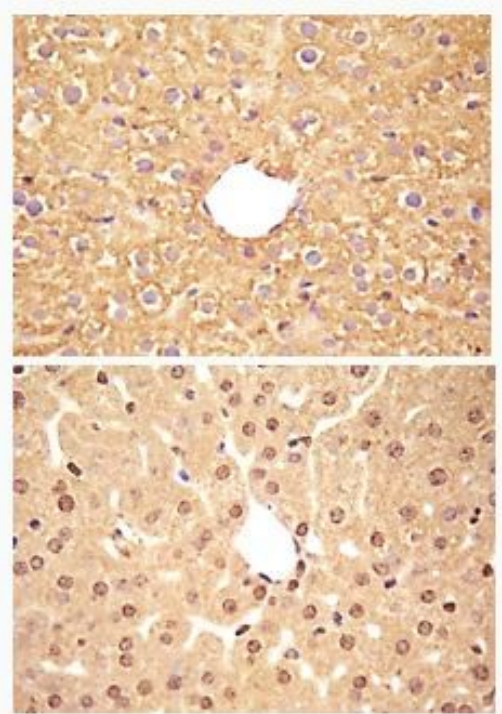

CLP

Figure 7 
Effects of D-CL on the histomorphology(HE staining, $\times 200$ ), the hepatocyte apoptosis (TUNEL, $\times 400)$ and the expression level of apoptosis related proteins in mice liver(immunohistochemistry, $\times 400)$. Mice were dosed daily with D-CL or CLP for 7 consecutive days(Loading dose: $120 \mathrm{mg} / \mathrm{kg}$ followed by maintenance dose of $30 \mathrm{mg} / \mathrm{kg}$ once daily in the morning for 6 days), the liver were stained with hematoxylin and eosin(n=3); Apoptosis were determined in strict accordance with the In Suit Cell Death Detection kit(Fluorescein) instructions, and green fluorescence was TUNEL stained positive cells $(n=3)$; The expressions of $\mathrm{Bcl}-2$, Bax and caspase- 3 in mice liver were determined by immunohistochemistry $(n=3)$. CLP: clopidogrel, D-CL: deuterium clopidogrel.

\section{Supplementary Files}

This is a list of supplementary files associated with this preprint. Click to download.

- Graphicalabstract.pdf 